\title{
Apresentação
}

ELALI, G.; VELOSO, M. Do sonha à realidade: a ANPARQ e os desafios da pesquisa e da pós-graduação na área de arquitetura e urbanismo no Brasil. Thésis, Rio de Janeiro, v. 1, n. 1, p. 8 -16, jan/jun. 2016

\section{Do sonho à realidade: A ANPARQ e os desafios da pes- quisa e da pós-graduação na área de Arquitetura e Urbanismo no Brasil}

\author{
Gleice Azambuja Elali \\ Maísa Veloso
}

Gleice Azambuja Elali é graduada em Arquitetura e Urbanismo (1982) e em Psicologia (1987) pela Universidade Federal do Rio Grande do Norte (UFRN), tem mestrado e doutorado em Arquitetura e Urbanismo pela Universidade de São Paulo (1996 e 2002). Atualmente é docente da UFRN, mantendo atividade didática e de pesquisa na graduação e pós-graduação, relacionada a Projeto Arquitetônico e Psicologia Ambiental. Temas de interesse: relações pessoa-ambiente como subsídio à projetação arquitetônica, avaliação do ambiente construído, percepção ambiental. Pesquisadora com bolsa de Produtividade do CNPq, vinculada aos grupos Inter-Ações Pessoa-Ambiente (UFRN) e Projetar (UFRN), participa da Associação Nacional de Pesquisa e Pós-graduação em Psicologia (ANPEPP - GT Psicologia Ambiental - coordenadora nas gestões 2008-2010 e 2010-2012), da Associação Nacional de Tecnologia do Ambiente Construído (ANTAC - GT Qualidade do Projeto) e da Associação Nacional de Pesquisa e Pós-graduação em Arquitetura e Urbanismo (ANPARQ - várias diretorias; presidente 2013/2014)

Maísa Veloso é Possui graduação em Arquitetura pela Universidade Federal de Pernambuco (1985), mestrado em Desenvolvimento Urbano pela Universidade Federal de Pernambuco (1992) e doutorado em Géographie, Aménagement du Territoire et Urbanisme - Université de Paris III (Sorbonne-Nouvelle) (1996). Atualmente, é Professora Associada da Universidade Federal do Rio Grande do Norte. Tem experiência na área de Arquitetura e Urbanismo, com ênfase em Planejamento e Projeto do Espaço Urbano e da Edificação, atuando principalmente nos seguintes temas: projeto de arquitetura e urbanismo, preservação e conservação do patrimônio edificado. Coordena o Grupo de Pesquisa PROJETAR Projeto de Arquitetura e Percepção do Ambiente - da UFRN, grupo fundador do evento que leva o seu nome PROJETAR - Seminário sobre Ensino e Pesquisa em Projeto de Arquitetura, cuja primeira edição ocorreu em Natal, em 2003, promovido pelo PPGAU/ UFRN. É membro fundador da ANPARQ - Associação de Pesquisa e Pós-Graduação em Arquitetura e Urbanismo - e integrante de sua primeira Diretoria.

Um sonho que se sonha só é só um sonho que se sonha só, mas sonho que se sonha junto é realidade.

(Prelúdio - Raul Seixas) 


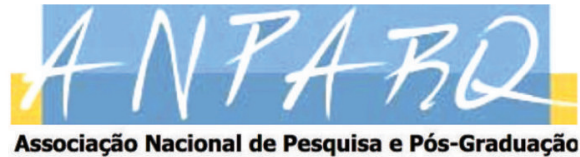

em Arquitetura e Urbanismo

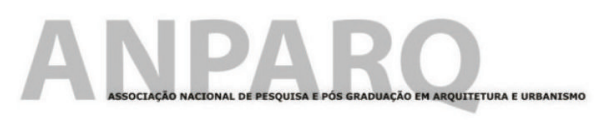

ANPARQ

ASSOCIAÇÃO NACIONAL DE PESQUISA E PÓS-GRADUAÇÃO EM ARQUITETURA E URBANISMO

Figura 1

Logos da ANPARQ
O convite para elaborar um texto para o primeiro número desta revista apresentando a Associação Nacional de Pesquisa e Pós-graduação em Arquitetura e Urbanismo (ANPARQ) configura-se como uma excelente oportunidade para contarmos um pouco da sua história, repensarmos nossa caminhada e, parafraseando o poeta, para relembrar que, partindo de uma ideia comum, sua construção foi uma obra coletiva, tendo exigido muitas mãos e muitas vozes para vir a se consolidar, atingindo o ponto em que hoje nos encontramos.

A Associação foi fundada em 12 de outubro de 2004 como uma entidade jurídica de direito privado e sem fins lucrativos que reúne filiados institucionais (programas de pós-graduação em AU), associados institucionais (entidades de pesquisa e instituições de áreas correlatas) e sócios individuais (pesquisadores), em 2014 a ANPARQ completou 10 anos de trajetória. Concluídas as fases da construção e consolidação, iniciamos agora uma nova etapa, e precisamos enfrentar seus desafios, mas sem esquecer nossos alicerces, e esperando utilizá-los como plataformas para novos e necessários voos.

A ANPARQ surgiu da iniciativa de professores e pesquisadores presentes na Plenária de Encerramento do I Seminário Projetar, realizado em outubro de 2003, em Natal/UFRN. Na ocasião foi formada uma comissão, capitaneada por Elvan Silva (UFRGS), para fazer uma proposta preliminar de associação de pesquisa, em atendimento a uma expectativa dos pesquisadores presentes que, há algum tempo, entendiam ser esta uma das carências da área. Após um ano de trabalho e muita discussão, a comissão elaborou a versão preliminar do estatuto e, ao registrá-la, passou a constituir o grupo fundador da ANPARQ, integrando sua primeira diretoria, considerada ainda provisória, sob a presidência de Elvan Silva. Este veio a falecer precocemente em abril de 2006, sendo a presidência assumida por Maísa Veloso.

Embora nos primeiros momentos a ideia fosse organizar uma associação de pesquisadores, durante esta fase inicial o debate foi gradativamente ampliado, passando a incluir os programas de pós-graduação, o que aumentou a abrangência da entidade, mas, também, a diversidade de expectativas e objetivos do grupo. As negociações voltadas para promover os ajustes necessários a essa situação se prolongaram por quase três anos. Apenas em outubro de2007, em Porto Alegre, o estatuto foi aprovado em assembleia, sendo eleita a primeira diretoria não provisória, tendo Carlos Alberto Ferreira Martins (IAU-USP) como presidente. Na ocasião, 16 programas de pós-gra- 
duação em AU se filiaram à ANPARQ, proporcionando um importante lastro institucional. Seguiram-se duas outras gestões, presididas por Gustavo Rocha Peixoto (UFRJ - 2010/2012) e por Gleice Azambuja Elali (UFRN - 2013/2014). Atualmente a associação é presidida por Angélica Benatti Alvim (UPM) e conta com 25 Programas filiados e 02 associados, além de 43 pesquisadores individuais.

\section{Diretorias provisórias da ANPARQ 2004-2007}

\begin{tabular}{|c|c|}
\hline $\begin{array}{c}\text { Diretoria Provisória } 1 \\
\text { 2004-2006 } \\
\end{array}$ & $\begin{array}{c}\text { Diretoria Provisória } 2 \\
\text { 2006-2007 }\end{array}$ \\
\hline $\begin{array}{l}\text { Presidente: } \\
\text { Elvan Silva (UFRGS) } \\
\text { Secretária: } \\
\text { Maísa Veloso (UFRN) } \\
\text { Tesoureiro: } \\
\text { Paulo Afonso Rheingantz (UFRJ) }\end{array}$ & $\begin{array}{l}\text { Presidente: } \\
\text { Maísa Veloso (UFRN) } \\
\text { Secretária: } \\
\text { Gleice Azambuja Elali (UFRN) } \\
\text { Tesoureiro: } \\
\text { Paulo Afonso Rheingantz (UFRJ) }\end{array}$ \\
\hline $\begin{array}{l}\text { Diretores: } \\
\text { Cristiane Rose S. Duarte (UFRJ) } \\
\text { Gleice Azambuja Elali (UFRN) }\end{array}$ & $\begin{array}{l}\text { Diretores: } \\
\text { Cristiane Rose S. Duarte (UFRJ) }\end{array}$ \\
\hline $\begin{array}{l}\text { Conselho Fiscal: } \\
\text { Leonardo Bittencourt (UFAL) } \\
\text { Nirce S. Medvedovski (UFPel) } \\
\text { Sonia Marques (UFRN) }\end{array}$ & $\begin{array}{l}\text { Conselho Fiscal: } \\
\text { Leonardo Bittencourt (UFAL) } \\
\text { Nirce S. Medvedovski (UFPel) } \\
\text { Sonia Marques (UFRN) }\end{array}$ \\
\hline
\end{tabular}

O Estatuto da ANPARQ expressa como suas finalidades básicas: "estimular, apoiar e incentivar atividades inerentes à formação, à pesquisa, à cultura e ao desenvolvimento cultural e tecnológico da área de Arquitetura e Urbanismo" (Art. $3^{\circ}$ ), buscando contribuir para o desenvolvimento/consolidação deste campo e a identificação de questões emergentes. Para tanto, entre outras ações, destacam-se:

- promover a divulgação de estudos e informações referentes à sua área de atuação;

- promover reuniões científicas periódicas e participar de eventos, objetivando o intercâmbio de informações entre seus associados e os de associações similares brasileiras, estrangeiras ou internacionais;

- organizar e promover atividades de cooperação, inclusive o intercâmbio de docentes e pesquisadores, entre os cursos de pós-graduação e outros núcleos, programas e órgãos nacionais, estrangeiros e internacionais de ensino e pesquisa;

- agir no interesse das entidades associadas e representá-las junto a órgãos públicos e privados. 


\section{Diretorias da ANPARQ 2007-2016}

\begin{tabular}{|c|c|c|c|}
\hline $\begin{array}{c}\text { Diretoria } 1 \\
2007-2009 \\
\end{array}$ & $\begin{array}{c}\text { Diretoria } 2 \\
2010-2012 \\
\end{array}$ & $\begin{array}{c}\text { Diretoria } 3 \\
2013-2014 \\
\end{array}$ & $\begin{array}{c}\text { Diretoria } 4 \\
2015-2016 \\
\end{array}$ \\
\hline $\begin{array}{l}\text { Presidente: } \\
\text { Carlos Alberto F. } \\
\text { Martins (USP) } \\
\text { Secretário: } \\
\text { Renato Anelli (USP) } \\
\text { Tesoureiro: } \\
\text { José Tavares C. de } \\
\text { Lira (USP) }\end{array}$ & $\begin{array}{l}\text { Presidente: } \\
\text { Gustavo } \\
\text { Rocha-Peixoto } \\
\text { (UFRJ) } \\
\text { Secretária: } \\
\text { Maria Cristina } \\
\text { Cabral (UFRJ) } \\
\text { Tesoureira: } \\
\text { Marlice de Azevedo } \\
\text { (UFF) }\end{array}$ & $\begin{array}{l}\text { Presidente: } \\
\text { Gleice Azambuja } \\
\text { Elali (UFRN) } \\
\text { Secretário: } \\
\text { Aluísio B. Melo } \\
\text { (UFPB) } \\
\text { Tesoureiro: } \\
\text { Márcio Cotrim Cunha } \\
\text { (UFPB) }\end{array}$ & $\begin{array}{l}\text { Presidente: } \\
\text { Angélica Benatti } \\
\text { Alvim (UPM) } \\
\text { Secretário: } \\
\text { Maria Cristina da S. } \\
\text { Schicchi } \\
\text { (PUC-Camp) } \\
\text { Tesoureiro: } \\
\text { Rachel Coutinho M. } \\
\text { da Silva (UFRJ) } \\
\end{array}$ \\
\hline $\begin{array}{l}\text { Diretores: } \\
\text { Maísa Veloso (UFRN) } \\
\text { José Ripper Kos } \\
\text { (UFRJ) } \\
\text { Cláudia P. Costa } \\
\text { Cabral (UFRGS) } \\
\text { Suplente: } \\
\text { Fernanda B. Moraes } \\
\text { (UFMG) }\end{array}$ & $\begin{array}{l}\text { Diretores: } \\
\text { Carlos Eduardo } \\
\text { Comas (UFRGS) } \\
\text { Gleice Azambuja } \\
\text { Elali (UFRN) } \\
\text { Ruth Verde Zein } \\
\text { (UPM) } \\
\text { Suplente: } \\
\text { Aluísio B. Mello } \\
\text { (UFPB) }\end{array}$ & $\begin{array}{l}\text { Diretores: } \\
\text { Angélica B. T. Alvim } \\
\text { (UPM) } \\
\text { Maria Cristina N. } \\
\text { Cabral (UFRJ) } \\
\text { Rodrigo Espinha } \\
\text { Baeta (UFBA) } \\
\text { Suplente: } \\
\text { Rodrigo Faria (UNB) }\end{array}$ & $\begin{array}{l}\text { Diretores: } \\
\text { Márcio Cotrim } \\
\text { Cunha (UFPB) } \\
\text { Renato Anelli (USP) } \\
\text { Cláudia Piantá } \\
\text { Costa Cabral } \\
\text { (UFRGS) } \\
\text { Suplente: } \\
\text { Maria de Lourdes } \\
\text { Zuquim (USP) }\end{array}$ \\
\hline $\begin{array}{l}\text { Conselho Fiscal: } \\
\text { Ruth Verde Zein } \\
\text { (UPM-SP) } \\
\text { Ceça Guimaraens } \\
\text { (UFRJ) } \\
\text { José B. Pessoa (UFF) } \\
\text { Suplente: } \\
\text { Anna Beatriz Galvão } \\
\text { (UFBA) }\end{array}$ & $\begin{array}{l}\text { Conselho Fiscal: } \\
\text { Fernando Diniz } \\
\text { (UFPE) } \\
\text { Helena Ayoub (USP) } \\
\text { Renato Anelli (USP) } \\
\text { Suplente: } \\
\text { Naia Alban (UFBA) }\end{array}$ & $\begin{array}{l}\text { Conselho Fiscal: } \\
\text { Gustavo Ro- } \\
\text { cha-Peixoto (UFRJ) } \\
\text { Luiz M. do E. } \\
\text { Amorim (UFPE) } \\
\text { Márcio Minto } \\
\text { Fabrício (USP) } \\
\text { Suplente: } \\
\text { Cláudia P. Costa } \\
\text { Cabral (UFRGS) }\end{array}$ & $\begin{array}{l}\text { Conselho Fiscal: } \\
\text { Gleice Azambuja } \\
\text { Elali (UFRN) } \\
\text { Angela Maria } \\
\text { Gordillo de Souza } \\
\text { (UFBA) } \\
\text { Maria Angela Dias } \\
\text { (UFRJ) } \\
\text { Suplente: } \\
\text { Rodrigo S. de Faria } \\
\text { (UNB) }\end{array}$ \\
\hline
\end{tabular}

Em consonância com estes objetivos, além de apoio institucional a diversos eventos, a associação tem organizado os Encontros Nacionais da ANPARQ (ENANPARQ), o Prêmio ANPARQ e os Seminários Nacionais de Pesquisa e Pós-graduação em AU (SeNAU), que apresentamos a seguir. Além deles, em comemoração aos 10 anos de existência da associação, surge agora a Thésis - revista da ANPARQ, concebida de modo a atender às exigências das agências brasileiras de fomento à pesquisa e, sobretudo, como resposta às reivindicações de nossos pesquisadores no sentido de fortalecermos a área de AU por meio do lançamento um periódico mais diretamente voltado para os seus interesses e áreas de pesquisa. 


\section{ENANPARQ}

O Encontro Nacional da ANPARQ é um evento científico bienal itinerante que acontece em anos pares, geralmente no segundo semestre, tendo como meta fomentar a discussão acerca dos saberes e fazeres do arquiteto-urbanista-paisagista na contemporaneidade. Os eventos são pensados para funcionarem como espaço de reflexão sobre as temáticas investigadas em nosso campo disciplinar, de modo a, não apenas analisar fatores que Ihe são inerentes, mas, sobretudo, fomentar novas questões a serem investigadas e promover o surgimento e a estruturação/consolidação de grupos e redes de pesquisa.

Desde seu início o evento tem se desenvolvido a partir de propostas de Simpósios Temáticos feitas por grupos de 03 a 05 pesquisadores interessados em problemáticas comuns, que configuram uma coluna vertebral a qual cada nova versão do encontro tem acrescentado outras modalidades de trabalho. Além disso, acontecem palestras, mesas redondas e lançamento de livros. O sucesso das suas primeiras edições fez com que o ENANPARQ logo se tornasse reconhecido como um importante evento científico na área de AU.

O I ENANPARQ aconteceu em novembro e dezembro de 2010, no Rio de Janeiro e foi promovido pelos programas de Arquitetura e Urbanismo da Universidade Federal do Rio de Janeiro (PROARQ/UFRJ e PROURB/ UFRJ) em parceria com a Universidade Federal Fluminense (PPGAU/UFF) sendo capitaneado por Denise Pinheiro Machado (UFRJ), sob o tema Arquitetura, Cidade, Paisagem e Território: percursos e prospectivas, foram reunidos cerca de 400 pesquisadores, professores e estudantes de pós-graduação e, além dos 35 simpósios apresentados em 05 sessões simultâneas, foram aceitos 40 artigos isolados, apresentados na forma de banners.

O II ENANPARQ, realizado em setembro de 2012 em Natal, foi promovido pelo PPGAU-UFRN, com a colaboração do PPGAU-UFPB e do MDU-UFPE, sob a presidência de Maísa Veloso (UFRN). A temática proposta foi Teorias e Práticas na Arquitetura e na Cidade Contemporâneas: Complexidade, Mobilidade, Memória e Sustentabilidade. Os simpósios continuaram dando a tônica do evento, mas, além dos pôsteres (dessa vez em formato digital), foi aberto um espaço para artigos enviados isoladamente, reunidos em sessões de comunicações. O II ENANPARQ congregou 494 participantes, 40 simpósios, 08 sessões de comunicação (somando 48 artigos) e 93 pôsteres, num total de 08 sessões simultâneas.
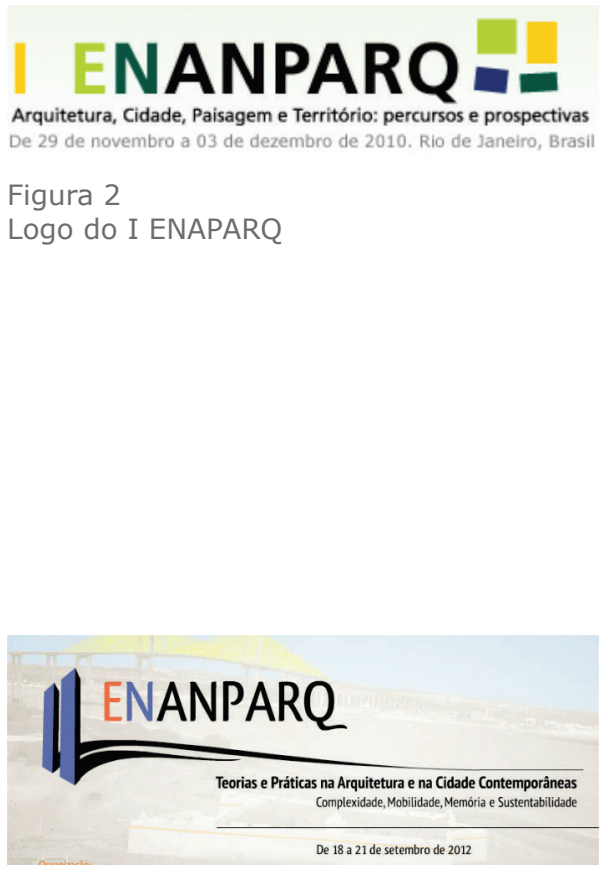

Figura 3

Logo do II ENAPARQ 


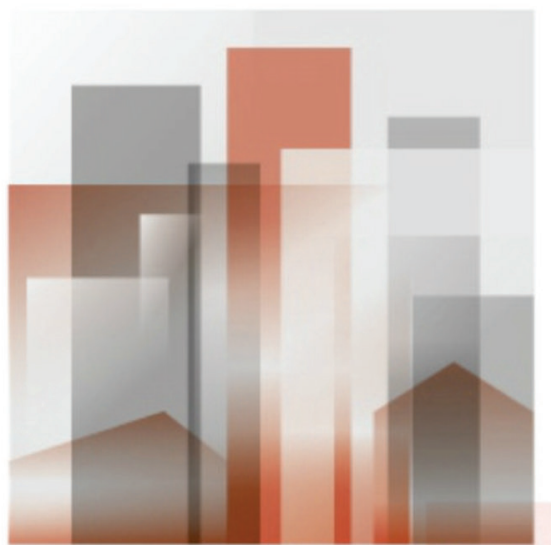

III ENANPARO arquitetura, cidade e projeto: uma construção coletiva

Figura 4

Logo do III ENAPARQ
O III ENANPARQ, ocorrido em São Paulo no mês de outubro de2014, teve coordenação de Angélica Benatti Alvim (UPM) e Wilson Ribeiro dos Santos Junior (PUC-Campinas), e contou com o apoio dos 7 programas de pós-graduação em AU do Estado: PPGAU/UPM, POSURB/PUC-Campinas, IAU/USP- São Carlos, PPGARQ/ UNESP, PPGATC/UNICAMP, PPGAU-FAUUSP e PPGAU/ USJT-SP. Vinculando-se à problemática urbana e às mudanças físicas e sociais advindas da contemporaneidade, o assunto tratado foi Arquitetura, cidade e projeto: uma construção coletiva. Tendo mais de 600 inscritos, a programação envolveu simultaneamente 14 salas de trabalho, num total de 46 simpósios e 243 artigos apresentados oralmente ou como pôsteres.

\section{Prêmio ANPARQ}

O Prêmio ANPARQ tem como objetivo reconhecer, premiar e divulgar a produção científica brasileira de excelência na área de Arquitetura e Urbanismo, sendo analisadas as seguintes modalidades de trabalho: tese, dissertação, livro (texto integral), livro (organização de coletânea), capítulo e artigo em periódico. Em suas duas primeiras edições, o prêmio foi coordenado pelos próprios organizadores dos ENANPARQ, esta situação foi alterada pela assembleia realizada em 2012 no fechamento do II ENANPARQ, que o tornou um concurso independente, embora a sessão de premiação continue a acontecer durante o evento.

A importância e reconhecimento da Prêmio ANPARQ podem ser claramente visíveis através do número de interessados em cada nova edição, que, entre 2010 e 2014, aumentou exponencialmente, tendo passado de 45 para 154 trabalhos inscritos (considerando o somatório de todas as categorias).

O Premio ANPARQ 2010 teve como principal organizadora Denise Pinheiro Machado (UFRJ). Nele se inscreveram 45 trabalhos, sendo premiados 07 e indicadas 20 menções honrosas distribuídas pelas diversas modalidades.

O Premio ANPARQ 2012 foi coordenado por Gleice Azambuja Elali (UFRN) e teve 87 inscritos. Foram premiados 07 trabalhos e aferidas 10 menções honrosas. Além disso, subcomissões especiais escolheram o meIhor artigo e o melhor pôster do II ENANPARQ, totalizando mais 03 prêmios e outras 06 menções honrosas. 
A presidência do Prêmio ANPARQ 2014 ficou a cargo deLuis Manuel do Eirado Amorim (UFPE), e o concurso recebeu 154 trabalhos. Nesta versão, o processo seletivo foi aperfeiçoado em função da gradativa ampliação número de concorrentes e do refinamento dos critérios de escolha das comissões julgadoras, sendo dividido em duas etapas.

Embora até este momento a premiação corresponda apenas a um certificado, nos próximos anos a meta é promover a publicação das teses e dissertações vencedoras.

\section{SeNAU}

Nos anos ímpares, entre os encontros nacionais (ENANPARQ), está prevista a realização do Seminário Nacional de Pesquisa e Pós-graduação em Arquitetura e Urbanismo (SeNAU), que habitualmente tem acontecido na cidade do seguinte encontro nacional da entidade. Consistindo em uma espécie de contraponto a eventos maiores, estes encontros geralmente contam com algo entre 50 e 150 participantes, em especial coordenadores de programas e docentes, tendo como objetivo a discussão aprofundada de algum tema de interesse da área.

O I SeNAU aconteceu em junho de 2009, em São Carlos, tendo como tema, Política de Indução à Pesquisa em AU e a Interação Universidade/Sociedade. Participaram cerca de 50 pesquisadores, dentre os quais 27 representantes de 14 programas de pós-graduação em AU. Além de mapear os PPGs na área e as possibilidades de fomento oficiais (FAPs/ CNPQ/ FINEP/ CAPES), foram discutidos formatos de programas específicos para a área e debatido o impacto dessa experiência sobre o campo profissional, quer na atuação em âmbito privado quanto no tocante às políticas públicas.

O II SeNAU aconteceu em julho de 2012, no Rio de Janeiro, (sua realização em 2011 foi inviabilizada por questões de fomento), com o objetivo de discutir a Difusão de pesquisa em Arquitetura e Urbanismo. O seminário teve 91 inscrições de docentes e discentes, dentre os quais representantes de 16 IES de nove diferentes estados brasileiros. Entre seus pontos conclusivos estavam: ampliar a difusão da produção na área; incentivar o aumento de fomentos dirigidos aos periódicos na área; promover a valorização da publicação em livros e anais de eventos; viabilizar a criação do periódico científico da ANPARQ. O seminário incluiu ainda, a OFICINA 3 - ABRIGOS (O3A), reunin-

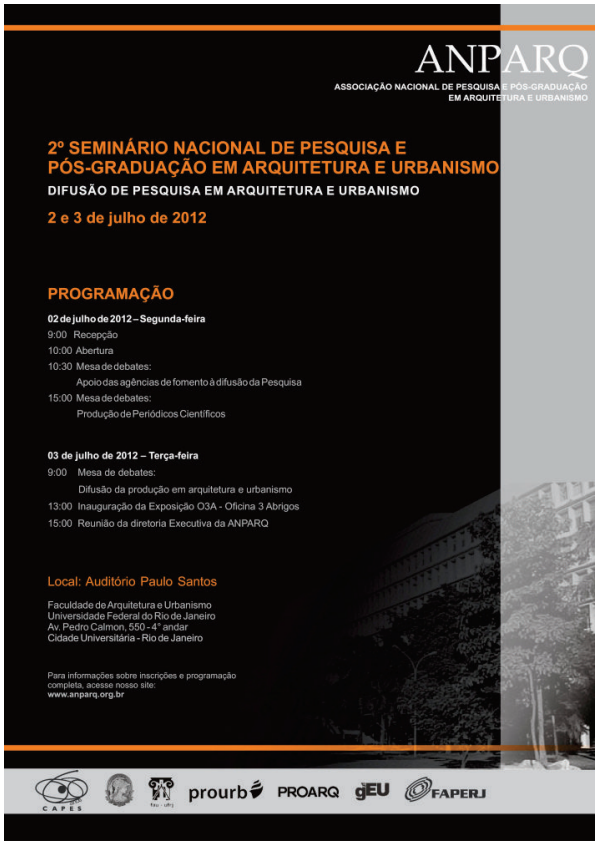

Figura 6

Cartaz do II SeNAU 


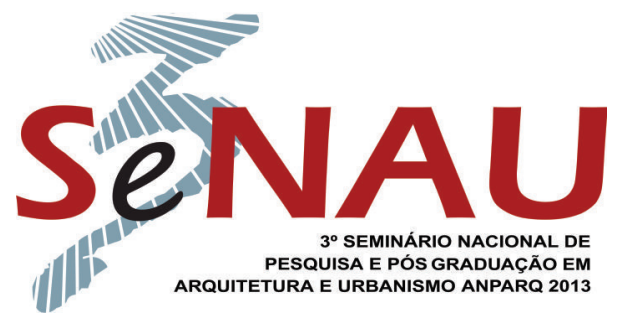

Figura 7

Logo do III SeNAU

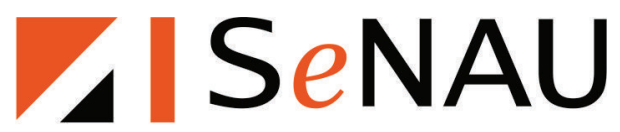

$4^{\circ}$ Seminário Nacional de Pesquisa e Pós Graduaçāo em Arquitetura e Urbanismo - ANPARQ 2015

inovação e ética na pesquisa em arquitetura e urbanismo

Figura 8

Logo do IV SeNAU do professores e alunos de 3 escolas de arquitetura e urbanismo (FAU/UFRJ, EAU/UFF e CAU/Puc-Rio), os quais realizaram instalações temporárias nos jardins da FAU, utilizando materiais descartáveis.

O III SeNAU ocorreu em Natal, em agosto de 2013, tendo debatido a Produção Bibliográfica em Arquitetura e Urbanismo. Seus 127 inscritos representaram 21 IES de 13 estados, com destaque para 21 coordenadores ou vice-coordenadores de PPGs em AU. Entre suas principais deliberações destacam-se:criar o periódico científico da ANPARQ; buscar meios para aumentar a eficácia da difusão da qualidade da produção na área de $A U$; incentivar a manutenção da diversidade da divulgação dos resultados das pesquisas na área, de modo a atingir públicos diferenciados; vaIorizar a publicação em livros e aumentar a eficiência de sua avaliação; (e) ampliar a discussão sobre a possibilidade de avaliação equânime dos diferentes tipos de publicação na área, em especial na relação entre periódicos e livros.

\section{Desafios para o futuro}

A análise desta trajetória de mais de uma década - na qual tivemos a oportunidade de acompanhar ativamente tanto como membros do grupo fundador quanto como participantes das diversas diretorias -, indica que, superados os desafios iniciais de sua fundação e construção como entidade jurídica representativa da pesquisa e da pós-graduação na área de Arquitetura e Urbanismo, a ANPARQ e os seus encontros científicos bienais constituem-se hoje, de fato, o principal fórum aglutinador da pesquisa e da produção científica neste campo. A leitura dos artigos publicados nos anais das três primeiras edições do ENANPARQ apresenta um retrato bastante significativo do que se faz e se pensa em termos de pesquisa e ensino de pós-graduação no Brasil. Complexidade e diversidade são palavras que expressam bem esse panorama.

No momento em que a associação completa 11 anos, o lançamento deste periódico corresponde a um marco muito significativo, indicando que mais uma meta foi alcançada. No entanto, como o final de uma etapa é sempre o ponto de início para outra, alguns desafios se colocam. Há um longo caminho a percorrer a fim de traduzir as demandas da área de AU de forma qualificada e divulgar amplamente os resultados do nosso trabalho, ultrapassando as fronteiras locais e regionais, e permitindo seu reconhecimento nacional e no exterior. 
DIFUSÃO DE

PESQUISA EM

ARQUITETURA

E URBANISMO

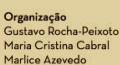

\section{ANPARP}

Figura 9

publicação "Difusão de pesquisa em Arquitetura e Urbanismo" elaborada a partir do material produzido no II SeNAU (Gustavo Rocha-Peixoto, Maria Cristina

Cabral e Marlice Azevedo)
Nesse sentido, por exemplo, a grande diversidade do campo da Arquitetura e Urbanismo, expressa no grande número de subáreas de conhecimento que abrange (projeto, paisagismo, teoria e história, tecnologia e outras), lança pelo menos dois grandes desafios a serem enfrentados em curto prazo: investir em uma melhor definição da sua identidade/especificidade, notadamente em relação a outras áreas muito próximas, como a de Planejamento Urbano e Regional, com a qual temos justaposições, mas também necessitamos estabelecer limites; promover o surgimento de mais periódicos qualificados que contemplem as diversas subáreas de conhecimento, ampliando as possibilidades de publicação, posto que duas ou três edições anuais d revista da ANPARQ ainda serão insuficientes para dar vazão à intensa produção neste campo.

Refletindo o amadurecimento da ANPARQ, é igualmente essencial o fortalecimento da sua participação nas agências de fomento à pesquisa e à pós-graduação, que precisa extrapolar a fase de reconhecimento e possibilitar uma atitude mais ativa e crítica, por meio de voz e voto nos processos de tomada de decisões ligadas à área. Espera-se, ainda, sua participação mais efetiva no meio sócio-político e profissional, abraçando mais fortemente as causas relacionadas à defesa da qualidade do ambiente, quer natural quer construído, e constituindo-se um agente de interlocução com outros campos.

Em síntese, entendemos que as principais metas a serem atingidas pela associação nos próximos anos relacionam-se, sobretudo a: estreitar os laços com outras instituições por meio da realização de trabaIhos conjuntos; reforçar sua missão científica a partir da difusão do conhecimento gerado pela formação e pesquisa pós-graduada; expandir seu papel social e político, com uma participação ativa nos processos e questões relacionados à área. Portanto, nossa expectativa para o futuro se faz no sentido da ANPARQ ampliar sua missão e modos de atuação em arquitetura e urbanismo, contribuindo, assim, para continuar a transformação do sonho coletivo em realidade. 